\title{
The effect of rearing substrate and space allowance on the behavior and physiology of dairy calves
}

\author{
M. A. Sutherland, ${ }^{1}$ G. M. Worth, and M. Stewart \\ AgResearch Ltd., Ruakura Research Centre, Hamilton 3214, New Zealand
}

\begin{abstract}
The objective of this study was to investigate the effect of rearing substrate and space allowance on the behavior and physiology of dairy calves. At 1 wk of age, 72 calves were moved into 1 of 18 experimental pens (n $=4$ calves $/$ pen) where they remained until 6 wk of age. Half of the pens had floors covered with quarry stones (QS) and the other half were covered with sawdust (SW). For each substrate type, calves were reared at 1 of 3 space allowances: $1.0,1.5$, or $2.0 \mathrm{~m}^{2} /$ calf. Behavior was video-recorded continuously for $24 \mathrm{~h}$ in the home pen at 2, 4, and 6 wk of age; the time calves spent lying, standing, walking, and running were estimated using 1-min instantaneous scan sampling. Body weight, cleanliness, fecal fluidity, and skin surface temperature were recorded at 1, 4, and 6 wk of age. Escherichia coli numbers were assessed on the skin surface of the shoulder and in feces of calves at 4 and 6 wk of age. Blood samples were taken at 1, 4, and 6 wk of age to measure cortisol, creatine kinase, immunoglobulin G, serum amyloid A, and total protein concentrations. Calves reared on QS spent less time lying and walking and more time standing at 4 and 6 wk of age compared with calves reared on SW. Furthermore, calves reared at a space allowance of $2.0 \mathrm{~m}^{2} /$ calf spent less time lying and more time standing and walking compared with calves reared at a space allowance of 1.0 and 1.5 $\mathrm{m}^{2} /$ calf. Calves reared on QS had lower skin surface temperatures compared with calves reared on SW. Fecal fluidity scores were lower in calves reared on QS than SW at 2 wk of age. Fewer E. coli were recovered from the shoulder of calves reared on QS than those of calves reared on SW, but fecal $E$. coli counts were similar between rearing substrates and space allowances. Serum amyloid A concentrations were lower in calves reared on QS than SW. We detected no effect of rearing substrate or space allowance on body weight, cleanliness, or concentrations of cortisol, creatine kinase, immunoglobulin G, and total protein. In conclusion, lower
\end{abstract}

Received December 11, 2013.

Accepted March 16, 2014.

${ }^{1}$ Corresponding author: mhairi.sutherland@agresearch.co.nz skin temperature in combination with reduced lying behavior may reflect reduced comfort of calves reared on QS. Furthermore, a space allowance of $2.0 \mathrm{~m}^{2} /$ calf may provide calves with more opportunity to perform active behaviors.

Key words: behavior, dairy calf, housing, welfare

\section{INTRODUCTION}

Housing and management practices during the preweaning period can affect the health and welfare of dairy calves. Important aspects of calf management and housing include rearing substrate and space allowance. Rearing substrates for calves evaluated in the literature include concrete, granite fines, rice hulls, rubber mats, sand, straw, stones, and wood shavings or sawdust (Panivivat et al., 2004; Hänninen et al., 2005; Hill et al., 2007, 2011; Camiloti et al., 2012; Sutherland et al., 2013). The type of substrate used in calf rearing facilities can affect calf cleanliness (Panivivat et al., 2004), weight gain and the incidence of diarrhea (Hill et al., 2011), skin surface temperature (Sutherland et al., 2013), and concentrations of acute phase proteins (Alsemgeest et al., 1995). Other factors associated with calf rearing substrates that could affect the health and welfare of calves include DM content, ammonia concentrations, substrate surface temperature, and bacteriology (Panivivat et al., 2004; Hill et al., 2011; Camiloti et al., 2012).

Substrate type used in rearing facilities can influence calf cleanliness, thermal comfort, and physiology. Panivivat et al. (2004) found that calves reared on granite fines had lower cleanliness scores than calves reared on sand, rice hulls, wheat straw, or wood shavings. Calves reared on river stones had lower skin surface temperatures than calves reared on sawdust, which may indicate reduced thermal comfort (Sutherland et al., 2013). In addition, Alsemgeest et al. (1995) found that serum amyloid A concentrations were affected by flooring type, with calves reared on a profiled durable plastic floor having higher concentrations than calves reared on a wooden floor with a rubber profile top layer.

Rearing substrate has been shown to influence behavior in dairy calves, with calves reared on rice hulls 
and sand spending more time self-grooming than calves reared on long wheat straw (Panivivat et al., 2004). Sutherland et al. (2013) found that calves reared on river stones spent less time performing locomotor play at $1 \mathrm{wk}$ of age and $4.5 \%$ less time lying at $5 \mathrm{wk}$ of age compared with calves reared on sawdust. Furthermore, dairy calves showed a clear preference for lying on dry sawdust and an aversion to lying on bare concrete (Camiloti et al., 2012).

Space allowance during the preweaning rearing period has been shown to influence BW and behavior of dairy calves. Body weight was higher in 35-d-old calves reared at a space allowance of $1.5 \mathrm{~m}^{2} /$ calf compared with calves reared at 2.25 and $4.0 \mathrm{~m}^{2}$ /calf (Tapkl et al., 2006). Tapkl et al. (2006) and Færevik et al. (2008) found no difference in lying times between calves reared at space allowances ranging from 0.75 to $4.0 \mathrm{~m}^{2} /$ calf; however, resting behavior was influenced by space allowance (Færevik et al., 2008). Tapkı et al. (2006) found that calves spent more time walking as space allowance increased. In addition, calves spent more time active (not lying down) and performing locomotor play as space allowance increased from 1.35 to $4.0 \mathrm{~m}^{2} /$ calf (Jensen et al., 1998).

In New Zealand (NZ), traditional rearing substrates, such as sawdust and wood shavings, are becoming difficult or expensive for farmers to obtain. Stones are an alternative rearing substrate used by some NZ dairy farmers because of cost, availability, and perceived improved calf health. However, there is limited scientific information available regarding the welfare implications of rearing calves on stones in relation to different management practices, such as space allowance. Therefore, the objective of this study was to investigate the effect of rearing calves on 2 substrate types (quarry stones and sawdust) at different stocking densities on calf behavior and physiology.

\section{MATERIALS AND METHODS}

\section{Animals, Housing, and Feeding}

This study was conducted between July and September 2012 at the AgResearch Dairy Research Farm, South Waikato $\left(175^{\circ} 1800^{\prime} \mathrm{E},-38^{\circ} 0300^{\prime} \mathrm{S}\right)$, NZ. All procedures involving animals were approved by the AgResearch Ruakura Animal Ethics Committee, under the NZ Animal Welfare Act (1999).

Seventy-two Friesian-cross dairy heifer calves were used in the study. The calves were separated from their dams within $24 \mathrm{~h}$ after birth and transported to the farm's calf rearing facility. Calves were kept in pens (15 calves per pen) with floors covered in woodchips before being moved to the experimental pens at approximately
$6 \mathrm{~d}$ of age. Six adjoining experimental group pens were constructed in the middle of the facility. These pens were constructed from wooden panels that allowed auditory, visual, olfactory, and some tactile contact between animals in adjoining pens. Each large pen was then subdivided into 3 smaller pens that would provide a space allowance of $1.0,1.5$, or $2.0 \mathrm{~m}^{2} /$ calf. Pens were separated by wooden panels and a steel, paneled gate. All pens had plastic troughs for water $(350 \mathrm{~mm}$ width $\times 300 \mathrm{~mm}$ length $\times 200 \mathrm{~mm}$ depth $)$ and feed $(310 \mathrm{~mm}$ width $\times 770 \mathrm{~mm}$ length $\times 260 \mathrm{~mm}$ depth) and these were attached to the side of the pen. All pens had dirt floors; in 3 of the large pens, the floor was covered with quarry stones (QS; Mangatangi River Rock Ltd., Auckland, NZ) with an approximate diameter of 40 to $60 \mathrm{~mm}$, and the other 3 large pens were covered with sawdust (SW) with an average particle size of $10 \mathrm{~mm}$. These are the estimates of stone size and particle size of the SW given by the suppliers. Rearing substrates were laid at a depth of approximately $30 \mathrm{~cm}$. The stones and sawdust had not previously been used at the beginning of the study.

Calves were fed $2 \mathrm{~L}$ of colostrum twice a day at 0800 and $1630 \mathrm{~h}$ for the first $4 \mathrm{~d}$ after birth. Thereafter, an equivalent amount of milk replacement was offered (SupaCalf, Fonterra Ltd., Auckland, NZ) using a 5-teat milk feeder (Stallion Plastic Ltd., Palmerston North, $\mathrm{NZ}$ ), which was removed after each feeding. Additionally, calves were given ad libitum access to a mixed feed of FiberStart (Fiber Fresh Feeds, Reporoa, NZ) consisting of $20 \% \mathrm{CP}, 4 \%$ crude fat, and $25 \%$ crude fiber, and Topcalf Formula 20 (Inghams Feed \& Nutrition, Hamilton, NZ) consisting of 20\% CP, 5\% crude fat, and $7 \%$ crude fiber. Water was provided ad libitum.

\section{Experimental Design}

At $6 \mathrm{~d}$ of age $( \pm 3 \mathrm{~d})$, calves $(38.4 \pm 0.84 \mathrm{~kg})$ were allocated to 1 of 6 treatment groups balanced for age and BW and then moved into the experimental pens containing QS or SW. For each substrate type, calves were reared at 1 of 3 space allowances: $1.0,1.5$, or 2.0 $\mathrm{m}^{2} /$ calf. The study was replicated 3 times and all treatments were represented during each replicate. For each replicate, 24 calves were tested simultaneously.

Environmental Conditions. The air temperature and ambient weather conditions in the barn were measured continuously during the trial period using weather stations (Vantage Pro2 Plus, Davis Instruments Corp., Hayward, CA) and portable Hobo Pro Data loggers (Onset Computer Corp., Bourne, MA). Four Hobo data loggers measuring rearing substrate surface temperature were located on each surface, in the middle of the barn and on the periphery. Two weather stations were 
located inside the barn and 1 was located outside to measure air temperature and relative humidity. Temperature data were recorded every $10 \mathrm{~min}$ over a 24 -h period during wk 2,4 , and 6 of the study period at the same time that behavior was recorded.

Behavioral Responses. Calf behavior was recorded continuously in real time at 30 frames/s for $24 \mathrm{~h}$ using overhead digital camcorders (Handycam Camcorder DCR-SX65, Sony, Tokyo, Japan) when calves were 2, 4, and 6 wk of age. Before behaviors were recorded, individual calves were marked using animal marking paint (Tell-Tail paint, FIL New Zealand, Mount Maunganui, NZ) for identification. The cameras were situated $2 \mathrm{~m}$ above the ground, fixed to stands that were attached to the side of the pens. Each camcorder was fitted with a fisheye lens $(0.3 \times$ conversion lens, QC-303 Snap-On, Raynox Digital, Tokyo, Japan) to ensure the entire pen was in view. Pens were lit between 2100 and $0800 \mathrm{~h}$ with 2 red light bulbs $(80 \mathrm{~W})$ to facilitate night observations with minimal effects on the calves' behavior. Video recordings were analyzed over the 24 -h period using 1-min scan sampling to estimate the percentage of time calves spent performing different behaviors at 2,4 , and 6 wk of age, including lying, standing, walking, running, eating, and drinking water. Behaviors are described in Table 1. Four trained people were used to analyze the video recordings and interobserver reliability was calculated; percentage of agreement between observers was between 98 and $100 \%$ for all behaviors.

Skin Surface Temperature. During wk 2, 4, and 6 of the study, temperature data loggers (Thermochron ibutton, model DS1921H-F5\#, range $15.0-46.0^{\circ} \mathrm{C}$, accuracy $\pm 1^{\circ} \mathrm{C}$, Embedded Data Systems, Lawrenceburg, $\mathrm{KY}$ ) were attached to calves to continuously measure skin surface temperature. Data loggers were attached to the chest of the calf, just behind the front legs. Hair was removed from the area and loggers were secured with a $5-\mathrm{cm}^{2}$ elastic adhesive bandage (Elastoplast, BSN Medical Inc., Hamburg, Germany). The bandages were further secured in the corners with glue (Kamar, Livestock Improvement Corporation, Hamilton, NZ). Data loggers were set to record temperatures every 10 min for $24 \mathrm{~h}$ during the same period that behavior was recorded.

BW, Cleanliness, and Fecal Score. Before being moved into the experimental pens and at 4 and 6 wk of age, calves were weighed and inspected by a veterinarian for clinical signs of disease and leg injuries, hair loss, and abnormalities. Hair loss on the knees and hocks was scored using a 5 -point scale: $1=$ normal, no hair loss; $2=$ hair whorls present; $3=$ hair loss $<1 \mathrm{~cm}$; $4=$ hair loss $>1 \mathrm{~cm}$; and $5=$ hair loss $>1 \mathrm{~cm}$, broken skin present.

A cleanliness score was recorded for all calves weekly using a scoring system adapted from Panivivat et al. (2004). Briefly, 1 = calf is clean (no dirt/manure present around the thighs or body, only manure present at the lower ends of legs), $2=$ dirt/manure is present around the tail head region and back of the calf, 3 $=$ dirt $/$ manure is present around the tail head region, thighs or legs of the calf, and $4=$ dirt/manure is present on the thighs, legs and tail head region of the calf.

A modified version of the fecal fluidity score developed by Larson et al. (1977) was used, where $1=$ normal, $2=$ soft and spreads slightly, $3=$ runny and spreads moderately, and $4=$ watery (severe diarrhea). Scores were recorded at 2 and 6 wk of age at the same time as fecal samples were collected for bacterial counts. A single observer scored all calves on every occasion.

Escherichia coli Count. For each calf, shoulder swab samples and fecal samples were collected at 2 and 6 wk of age. The shoulder swab samples were obtained by rubbing a sterile sponge over a $100-\mathrm{cm}^{2}$ area of the shoulder following the AgResearch Micromanual (2005) protocol for swabbing a large surface area. Individual sponges were homogenized by stomaching (Colworth Stomacher 400, Seward Ltd., West Sussex, UK) for 2 min with $180 \mathrm{~mL}$ of sterile milliQ water (Millipore, Billerica, MA). A composite suspension was obtained for each pen by combining an equivalent volume (30 $\mathrm{mL}$ ) of each stomached suspension obtained from the 4 calves in the pen. The resultant pen composite suspension was diluted in sterile milliQ water $(1: 10$ and $1: 100)$.

Table 1. Description of behaviors recorded by 1 min scan sampling over a 24 -h observation period

\begin{tabular}{ll}
\hline Behavior & Description \\
\hline Lying & Flank is in contact with ground. No weight supported by any hooves. \\
Standing & Weight supported by at least one hoof. No translocation of body. \\
Walking & A slow 4-beat gait with continuous forward movement for at least $2 \mathrm{~s}$. \\
Running & Rapid 4-beat gait with forward or sideways movement. Lasting longer than $1 \mathrm{~s}$ in real time. \\
Drinking water & Calf's head is situated over the water trough. \\
Eating pellets & Calf's head is situated over the feed trough. \\
\hline
\end{tabular}

${ }^{1}$ Definitions are based on the ethogram presented in Jensen et al. (1998). 
Fecal samples were obtained by direct retrieval, and the fecal sample was transferred to individual sterile containers. All samples were transported to the laboratory in an insulated box and analyzed within $24 \mathrm{~h}$ of collection. A composite fecal sample was obtained for each pen by combining $2 \mathrm{~g}$ of feces collected from each calf in the pen. The resultant pen composite feces were diluted in sterile milliQ water (to $10^{-5}$ and $10^{-7}$ ).

The number of $E$. coli in the diluted pen composite suspension from the shoulder swabs and in the diluted composite feces were measured by a most probable number method using the Colilert/Quantitray 2000 (Idexx Laboratories Inc., Westbrook, ME). The number of E. coli $100 \mathrm{~mL}$ of composite suspension or number of E. coli/100 g of composite feces was obtained from the tables supplied by the manufacturer.

Physiological Responses. Blood samples (10 mL) were obtained at 1, 4, and 6 wk of age (approximately $3 \mathrm{~h}$ after morning feeding) by jugular venipuncture and collected into one additive-free evacuated tube (BD Vacutainer, Franklin Lakes, NJ) to measure cortisol, creatine kinase, IgG, serum amyloid A, and total protein concentrations. Samples were held at ambient temperature following collection for up to $2 \mathrm{~h}$ to allow clotting and then centrifuged at 1,500 $\times g$ for $10 \mathrm{~min}$ at ambient temperature. Serum was then aspirated and aliquots were stored at $-20^{\circ} \mathrm{C}$ for future analysis.

Cortisol concentrations were measured using a commercially available solid-phase single-antibody RIA kit (Coat-a-Count Cortisol; Siemens, Los Angeles, CA). Creatine kinase, IgG, serum amyloid A, and total protein concentrations were analyzed using colorimetric techniques performed on a Hitachi Modular P800 analyzer at $37^{\circ} \mathrm{C}$ (Roche Diagnostics, Indianapolis, IN) by Gribbles Veterinary Pathology Ltd. (Hamilton, NZ).

\section{Statistical Analysis}

Data were analyzed by ANOVA using GenStat (13th ed., VSN International Ltd., Hemel Hempstead, UK). Pen was the experimental unit. All analyses were fitted for treatment (rearing substrate and space allowance) and age comparisons, and rearing substrate $\times$ space allowance and treatment $\times$ age interactions. A splitplot analysis fitting pen as the main plot and calf as the sub-plot was used. To compare ages, a repeatedmeasures ANOVA using a split-split plot analysis with pen as the main effect, calf as the sub-plot, and age as the sub-subplot was performed. The treatment differences were tested against the pen residual mean square (10 df). All data were tested for constant variance and departures from normal distribution. Departures from normality were assessed by inspecting plots of fitted values against residuals from the analysis. Statistical significance was determined at $P \leq 0.05$.

\section{RESULTS}

\section{Behavioral Responses}

Calves reared on QS spent less time lying and walking $(P<0.05)$ and more time standing $(P<0.05)$ at 4 and 6 wk of age compared with calves reared on SW, irrespective of space allowance (Table 2). Calves reared at a space allowance of $2.0 \mathrm{~m}^{2} /$ calf spent less time lying $(P<0.05)$ and more time standing $(P<0.05)$ at 2 and 6 wk of age compared with calves reared at a space allowance of 1.0 and $1.5 \mathrm{~m}^{2} /$ calf, irrespective of rearing surface. Furthermore, calves reared at a space allowance of $2.0 \mathrm{~m}^{2} /$ calf spent more $(P<0.05)$ time walking at 4 and 6 wk of age compared with calves reared at a space allowance of $1.0 \mathrm{~m}^{2} /$ calf (Table 2).

\section{Skin Surface Temperature}

Calves reared on QS had lower $(P=0.018)$ skin surface temperatures compared with calves reared on SW throughout the 6 -wk study period (Table 3 ). Space allowance had no effect $(P>0.05)$ on skin surface temperature in calves (Table 3 ).

\section{BW, Cleanliness, and Health}

Body weight did not differ $(P>0.05)$ among calves reared on QS or SW, or among calves reared at a space allowance of $1.0,1.5$, or $2.0 \mathrm{~m}^{2} /$ calf, regardless of age (1, 4, or 6 wk of age; Table 3). Calf BW increased with age. All calves were clean; no calf scored $>2$ on the cleanliness score scale regardless of substrate type, space allowance, or age. No calf showed any clinical signs of disease, lameness, leg lesions or injury, or abnormalities at wk 1, 4, or 6 , regardless of substrate type or space allowance. However, calves reared on QS had higher hair loss scores on the knee $(P=0.002$; QS: 1.9 \pm 0.17 ; SW: $1.0 \pm 0.17)$ and hock $(P=0.002$; QS: 1.1 \pm 0.02 ; SW: $1.0 \pm 0.02$ ) areas at 6 wk of age compared with calves reared on SW. Furthermore, calves reared at $2.0 \mathrm{~m}^{2} /$ calf had higher $(P=0.004)$ hair loss scores on the hock area than calves reared at 1.0 and $1.5 \mathrm{~m}^{2} /$ calf $\left(1.0 \mathrm{~m}^{2} /\right.$ calf: $1.0 \pm 0.02 ; 1.5 \mathrm{~m}^{2} /$ calf: $1.0 \pm 0.02 ; 2.0$ $\mathrm{m}^{2} /$ calf: $\left.1.1 \pm 0.02\right)$.

Fecal fluidity scores were lower $(P=0.036)$ in calves reared on QS than SW at 2 wk of age (QS: $1.3 \pm 0.23$; SW: $1.9 \pm 0.23)$, but we found no difference $(P>0.05)$ at 6 wk of age (QS: $1.2 \pm 0.10 ;$ SW: $1.3 \pm 0.10)$. Fecal fluidity scores were not affected $(P>0.05)$ by space allowance or calf age. 
Table 2. Behaviors (LSM \pm SEM) performed by calves reared on stones (QS: $\mathrm{n}=36$ ) or sawdust (SW: $\mathrm{n}=36)$ or at a space allowance of 1.0 , 1.5 , or $2.0 \mathrm{~m}^{2} /$ calf $(\mathrm{n}=24$ calves/space allowance) during a 24 -h observation period at 2,4 , and 6 wk of age

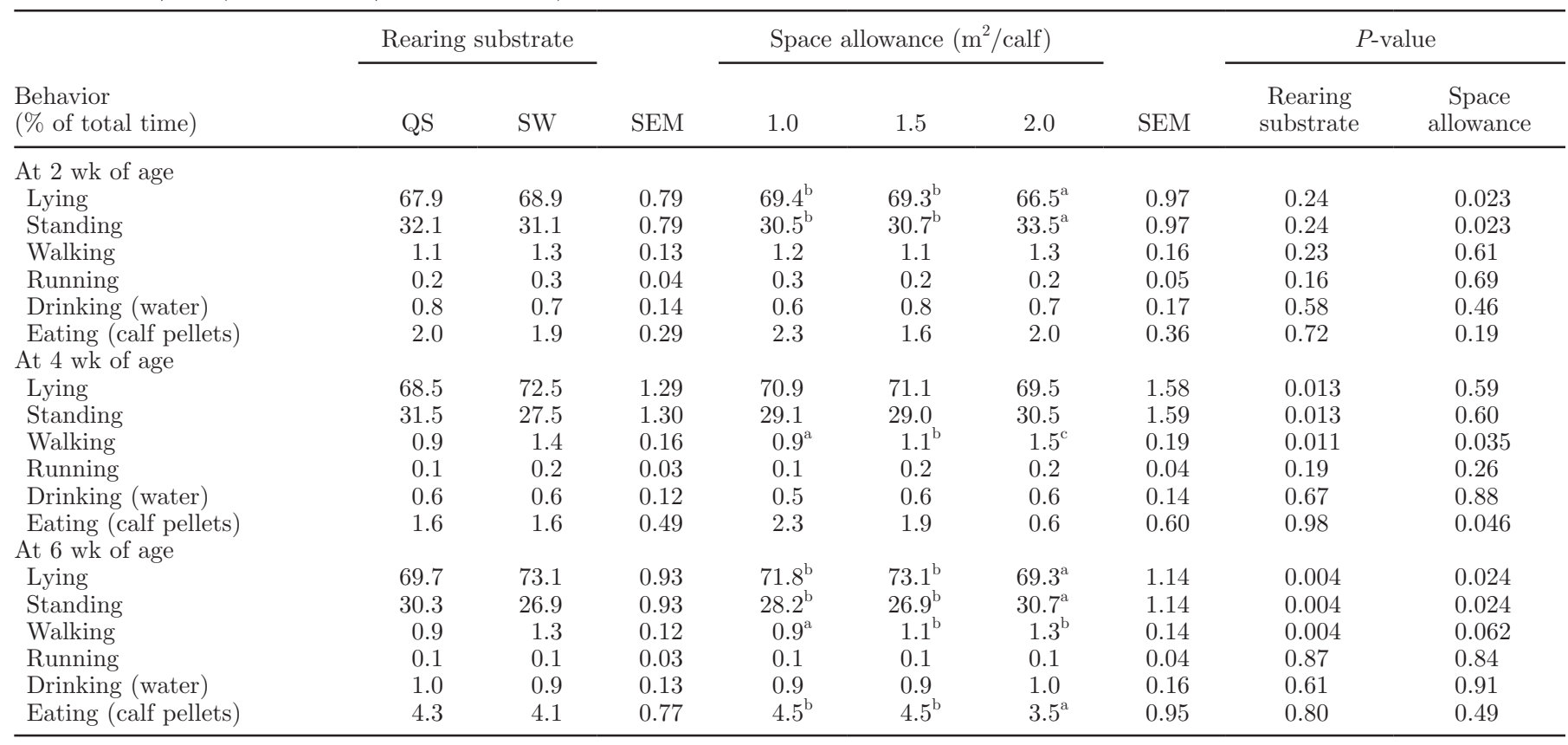

${ }^{a-c}$ Means within row with different superscripts differ at $P<0.05$.

\section{E. coli Counts}

The number of $E$. coli recovered from a surface area of $100 \mathrm{~cm}^{2}$ on the shoulder of each calf was not affected $(P>0.05)$ by space allowance, but fewer $(P<0.001) E$. coli were recovered from the shoulders of calves reared on QS than those of calves reared on SW at 4 and $6 \mathrm{wk}$ of age (Table 4). Fecal E. coli counts were not affected by rearing substrate, space allowance, or age $(P>0.05$; Table 4).

\section{Physiological Responses}

Cortisol, creatine kinase, IgG, and total protein concentrations were not different $(P>0.05)$ irrespective of rearing substrate, space allowance, or age (Table 3). However, serum amyloid A concentrations were lower $(P<0.05)$ in calves reared on QS than SW, irrespective of space allowance or age (Table 3 ).

\section{Environmental Conditions}

Values for environmental conditions, surface temperature of substrate, and DM are summarized as means \pm standard deviations. Temperature inside the calf rearing facility averaged $10.6 \pm 3.15^{\circ} \mathrm{C}$ during the second week, $12.2 \pm 2.03^{\circ} \mathrm{C}$ during the fourth week, and $11.3 \pm 2.46^{\circ} \mathrm{C}$ during the sixth week of the study period. Relative humidity inside the calf rearing facility averaged $87.3 \pm 7.12 \%$ during the second week, $90.0 \pm$

Table 3. Skin surface temperature, BW, and physiology $(\mathrm{LSM} \pm \mathrm{SEM})$ of calves reared on stones $(\mathrm{QS}: \mathrm{n}=36)$ or sawdust $(\mathrm{SW}: \mathrm{n}=36)$ or at a space allowance of $1.0,1.5$, or $2.0 \mathrm{~m}^{2} /$ calf $(\mathrm{n}=24$ calves/space allowance)

\begin{tabular}{|c|c|c|c|c|c|c|c|c|c|}
\hline \multirow[b]{2}{*}{ Item } & \multicolumn{2}{|c|}{ Rearing substrate } & \multirow[b]{2}{*}{ SEM } & \multicolumn{3}{|c|}{ Space allowance $\left(\mathrm{m}^{2} /\right.$ calf $)$} & \multirow[b]{2}{*}{ SEM } & \multicolumn{2}{|c|}{$P$-value } \\
\hline & QS & SW & & 1.0 & 1.5 & 2.0 & & $\begin{array}{l}\text { Rearing } \\
\text { substrate }\end{array}$ & $\begin{array}{c}\text { Space } \\
\text { allowance }\end{array}$ \\
\hline Skin temperature $\left({ }^{\circ} \mathrm{C}\right)$ & 32.0 & 32.9 & 0.30 & 32.1 & 32.8 & 32.5 & 0.37 & 0.018 & 0.25 \\
\hline \multicolumn{10}{|l|}{$\mathrm{BW}(\mathrm{kg})$} \\
\hline $1 \mathrm{wk}$ of age & 38.2 & 38.6 & 0.84 & 37.8 & 37.6 & 39.8 & 1.03 & 0.67 & 0.10 \\
\hline 4 wk of age & 49.1 & 50.1 & 0.83 & 48.8 & 49.2 & 50.8 & 1.02 & 0.29 & 0.17 \\
\hline Creatine kinase $(\mathrm{IU} / \mathrm{L})$ & 206 & 203 & 47.9 & 214 & 165 & 234 & 58.6 & 0.96 & 0.50 \\
\hline Total protein $(\mathrm{g} / \mathrm{L})$ & 57.3 & 59.5 & 1.09 & 59.9 & 57.9 & 57.5 & 1.34 & 0.071 & 0.22 \\
\hline $\mathrm{IgG}(\mathrm{g} / \mathrm{L})$ & 1,250 & 1,215 & 51.1 & 1,235 & 1,272 & 1,191 & 53.9 & 0.51 & 0.31 \\
\hline Serum amyloid $\mathrm{A}(\mu \mathrm{g} / \mathrm{mL})$ & 3.6 & 3.7 & 0.07 & 3.7 & 3.6 & 3.7 & 0.08 & 0.048 & 0.26 \\
\hline
\end{tabular}


Table 4. Number of Escherichia coli (LSM $\pm \mathrm{SEM})$ on the shoulder and in the feces of calves reared on stones (QS: $\mathrm{n}=36)$ or sawdust (SW: $\mathrm{n}=36)$ or at a space allowance of $1.0,1.5$, or $2.0 \mathrm{~m}^{2} /$ calf $(\mathrm{n}=24$ calves/space allowance $)$

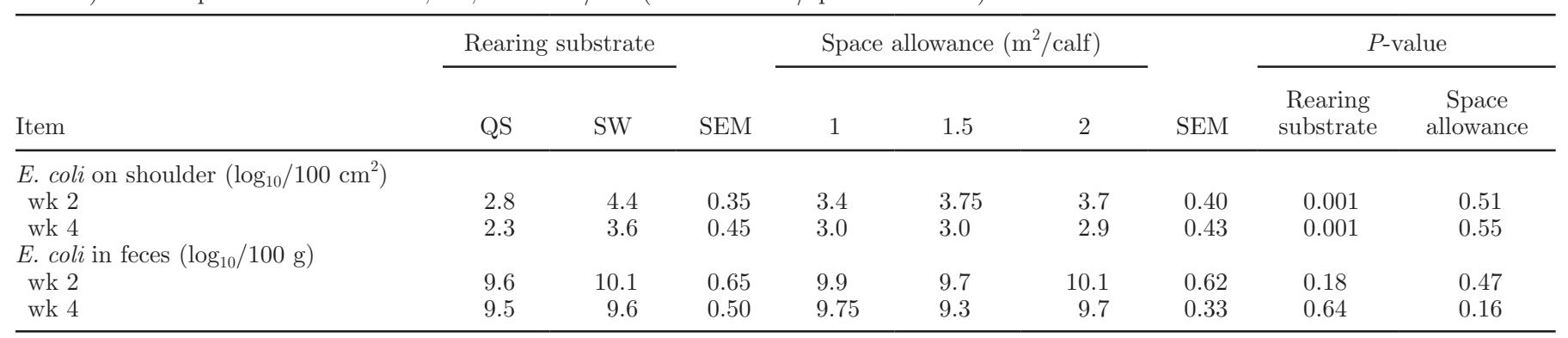

$6.43 \%$ during the fourth week, and $83.0 \pm 5.94 \%$ during the sixth week of the study period. Over the study period, surface temperature and relative humidity of the rearing substrate did not differ $(P>0.05)$ between QS and SW pens at any time point (QS: $11.2 \pm 2.69^{\circ} \mathrm{C}$; SW: $11.1 \pm 2.75^{\circ} \mathrm{C}$; and QS: $80.3 \pm 10.00 \%$; SW: 81.2 $\pm 9.77 \%)$. Moisture content of the sawdust was similar $(P>0.05)$ between all 3 space allowances $\left(1.0 \mathrm{~m}^{2} /\right.$ calf: $66.5 \pm 4.78 \% ; 1.5 \mathrm{~m}^{2} /$ calf: $64.9 \pm 1.39 \% ; 2.0 \mathrm{~m}^{2} /$ calf: $63.8 \pm 3.49 \%)$.

\section{DISCUSSION}

In NZ, QS are an alternative rearing substrate used by some dairy farmers. However, limited scientific information is available regarding the welfare implications of rearing calves on QS in relation to different management practices, such as space allowance. In the present study, we used behavior and physiology to investigate the effect of rearing calves on QS at different space allowances. Calves reared on QS spent less time lying and walking, had lower skin surface temperatures, and fewer $E$. coli were recovered from the surface of the shoulder. Calves reared at a space allowance of 2.0 $\mathrm{m}^{2} /$ calf spent less time lying and more time walking. Calf BW, cleanliness, and health were similar between calves reared on QS and SW and among calves reared at a space allowance of $1.0,1.5$, or $2.0 \mathrm{~m}^{2} /$ calf.

Lying behavior can be used as an indication of dairy cow comfort (Haley et al., 2001; Norring et al., 2008; Tucker et al., 2009); therefore, lying behavior maybe a useful indicator of dairy calf comfort in relation to different rearing substrates. Substrate type affected lying behavior in 4- and 6-wk-old calves in the present study; calves reared on QS spent 3.5 to $4.0 \%$ less time lying than calves reared on SW. Similarly, Sutherland et al. (2013) found that calves reared on river stones spent $4.5 \%$ less time lying than calves reared on $\mathrm{SW}$ at $5 \mathrm{wk}$ of age. However, Panivivat et al. (2004) found similar lying times among calves reared on 5 different surface types, including granite fines and wood shavings, at 1 to 6 wk of age. Resting behavior was also similar between calves reared on concrete or rubber mats over the first 20 wk of life (Hänninen et al., 2005). Several studies have shown that adult dairy cows spend more time lying when soft, compressible bedding materials are provided (Haley et al., 2001; Norring et al., 2008; Tucker et al., 2009). Dairy calves also showed a clear preference for dry SW lying surfaces and an aversion to concrete (Camiloti et al., 2012). Therefore, reduced lying time observed in calves reared on QS is likely related to the hardness or incompressibility of the rearing substrate and maybe associated with reduced calf comfort.

Space allowance has been shown to influence growth and behavior, including locomotor play, in dairy calves during the preweaning rearing period (Jensen et al., 1998; Tapkı et al., 2006; Færevik et al., 2008). Currently, there are no guidelines for space allowances for rearing calves in NZ, but the industry standard is approximately $1.0 \mathrm{~m}^{2} /$ calf and an allowance of $1.5 \mathrm{~m}^{2} /$ calf is recommended (On-Farm Research, 2013). Therefore, in the present study, we wanted to compare the NZ industry standard space allowance $\left(1.0 \mathrm{~m}^{2} /\right.$ calf $)$ with the recommended allowance $\left(1.5 \mathrm{~m}^{2} /\right.$ calf $)$ and a larger space allowance $\left(2.0 \mathrm{~m}^{2} /\right.$ calf $)$. Calves reared at the larger space allowance of $2.0 \mathrm{~m}^{2} /$ calf spent up to $2.9 \%$ less time lying and 3.0 and $0.6 \%$ more time standing and walking, respectively, compared with calves reared at a space allowance of $1.0 \mathrm{~m}^{2} /$ calf. Tapkı et al. (2006) and Færevik et al. (2008) found no difference in lying times between calves reared at space allowances ranging from 1.5 to $4.0 \mathrm{~m}^{2} /$ calf and 0.75 to $1.75 \mathrm{~m}^{2} /$ calf, respectively. However, Tapki et al. (2006) found that calves spent more time walking as space allowance increased from 1.5 to $4.0 \mathrm{~m}^{2} /$ calf. Jensen et al. (1998) also found that calves spent more time active (not lying down) and performed more locomotor play as space allowance increased from 1.35 to $4.0 \mathrm{~m}^{2} /$ calf. In the present study, calves reared at $2.0 \mathrm{~m}^{2} /$ calf spent more time standing and walking, suggesting that the increase in available space in these larger pens may have provided calves more opportunity to perform their normal range of natural behaviors, thereby enhancing 
animal welfare. However, further research is needed to investigate the optimum space requirements for rearing group-housed dairy calves.

Calves reared on QS had lower skin surface temperatures than calves reared on SW; however, we found no difference between the surface temperatures of the substrate types. These results are consistent with the findings of Sutherland et al. (2013). Differences in skin surface temperature may be related to the thermal properties of the different substrate types. For example, SW has greater insulation properties than QS, and QS may increase heat loss through conduction. In the present study, temperature inside the calf rearing facility averaged 10 to $12^{\circ} \mathrm{C}$. At these low ambient temperatures, rearing substrates with insulating rather than conductive properties are likely to be preferable to reduce the risk of cold stress, especially in young animals. Alternatively, in hot climates, substrates that conduct heat away from the animal maybe more desirable to reduce the risk of heat stress. Lower skin surface temperature in combination with reduced lying times observed in calves reared on QS suggests that these animals may experience reduced thermal comfort.

Calf BW was similar between the 2 substrate types in the present study. This is consistent with other studies comparing BW of calves reared on different substrates: river stones versus SW (Sutherland et al., 2013); granite fines, sand, rice hulls, wheat straw, or wood shavings (Panivivat et al., 2004); or concrete versus rubber mats (Hänninen et al., 2005). Space allowance also had no effect on calf BW in the present study. Conversely, BW was higher in 35-d-old calves reared at a space allowance of 1.5 compared with those reared at 2.25 and 4.0 $\mathrm{m}^{2}$ /calf; however, feed intake and weight gain were not affected by space allowance (Tapkı et al., 2006). In the present study, calves were fed $2 \mathrm{~L}$ of milk/calf twice a day, following normal farm practice, and calves were observed during feeding to ensure that all calves got their allocated portion. This may have contributed to the similarities in BW.

Calves reared on QS or SW did not score higher than 2 on a 4-point scale when using a cleanliness scoring system that took into account the amount of dirt or manure on the hide of the calf (Panivivat et al., 2004). Calf cleanliness was also similar between calves reared on river stones or SW (Sutherland et al., 2013). However, Panivivat et al. (2004) found that calves reared on granite fines had lower cleanliness scores than calves reared on sand, rice hulls, wheat straw, or wood shavings, which they attributed to the lower absorptive capacity of the granite fines. The size of the QS used in the present study and the river stones used by Sutherland et al. (2013) likely provided sufficient drainage of manure to prevent accumulation of manure on top of the stones and thus transfer to the coat of the calves. We predicted that calf cleanliness would decrease as space allowance decreased; however, calf cleanliness was similar at all 3 space allowances. This could be attributed to calves being reared following best management practices in the present study and the overall cleanliness of the animals.

In the present study, we observed no difference in clinical disease or leg health between calves reared on QS or SW; however, calves reared on QS had lower fecal fluidity scores at 2 wk of age. Panivivat et al. (2004) reported that during wk 2 calves reared on granite fines and sand had more diarrhea days (fecal fluidity score $>2$ ) compared with calves reared on rice hulls, wheat straw, or wood shavings. Hill et al. (2011) also found that calves reared on sand had higher abnormal fecal score days (fecal score $>2$ ) than calves reared on straw. Fecal scores of 2 -wk-old calves in the present study were $<2$ (soft and spreadable) on average; therefore, compared with other studies, these scores would not be considered indicative of diarrhea or abnormal fecal scores.

At 6 wk of age, hair loss on the knees and hock regions was observed in calves reared on QS but not calves reared on SW and it was greater in calves reared at $2.0 \mathrm{~m}^{2}$ /calf. Calves were kept on QS and SW for an extra 2 wk to assess whether areas of hair loss would become lesions due to loss of integrity of the skin, but this did not occur (data not presented). Hair loss was likely caused by the rubbing of the hair against the hard surface of the QS when calves knelt to lie down. Sutherland et al. (2013) did not report hair loss on the legs of calves reared on river stones, which could be due to differences in the source and quality of the stones used in these studies. Sutherland et al. (2013) reported using river stones that were sourced from a river, were approximately $30 \mathrm{~mm}$ in length, and were rounded with a smooth surface, whereas the QS in the present study were sourced commercially from a quarry, were approximately 40 to $60 \mathrm{~mm}$ in diameter, and were rounded with a slightly rough surface.

Fewer E. coli were recovered from the shoulders of calves reared on QS. Panivivat et al. (2004) reported that on d 42, wheat straw had the highest coliform counts; however, counts of gram-negative bacteria and coliforms differed between granite fines, sand, rice hulls, wheat straw, and wood shavings before calves used the pens. In the present study, fecal E. coli counts were similar between calves reared on QS and SW; therefore, rearing substrate did not affect fecal shedding of $E$. coli. However, SW may naturally have higher E. coli numbers than QS or have higher absorbency for bacterial growth, thereby increasing the likelihood of transfer of $E$. coli from the SW to the hide of the calf. A higher 
number of $E$. coli recovered from the shoulders of calves reared on SW was not associated with an increased incidence of diarrhea or other health-related issues; therefore, further studies with larger animal numbers are necessary to investigate the effect of rearing calves on QS on the incidence of disease.

Rearing substrate and space allowance did not affect concentrations of cortisol, creatine kinase, IgG, or total protein, which are indices of stress, tissue damage, the immune response, and protein homeostasis, respectively. Similarly, Panivivat et al. (2004) found no effect of rearing substrate on cortisol or IgG concentrations in dairy calves when 5 different surface types were compared. Alsemgeest et al. (1995) also found that cortisol concentrations were similar between calves reared on 2 different types of flooring (profiled durable plastic floor or a wooden floor with a rubber profile top layer). Therefore, the rearing substrates used and the space allowances tested in the present study did not appear to differentially affect the stress or immune response, cause tissue damage, or alter protein homeostasis.

Serum amyloid $\mathrm{A}$ is an acute phase protein and an indicator of disease and inflammation. In the present study, serum amyloid A concentrations were lower in calves reared on QS than in calves reared on SW. Alsemgeest et al. (1995) found that serum amyloid A concentrations were affected by flooring type, with calves reared on a profiled durable plastic floor having higher concentrations than calves reared on a wooden floor with a rubber profile top layer. However, in the present study, serum amyloid A concentrations were only 3.6 and $3.7 \mu \mathrm{g} / \mathrm{mL}$ in calves reared on QS and SW, respectively. Heegaard et al. (2000) reported baseline values for serum amyloid A below $17 \mu \mathrm{g} / \mathrm{mL}$ in dairy calves and peak concentrations of 60 to $80 \mu \mathrm{g} / \mathrm{mL}$ in response to an experimental infection with bovine respiratory syncytial virus. Therefore, in the present study, it is likely that the difference in serum amyloid A concentrations is not biologically significant and does not signify a disease challenge or increased inflammation, irrespective of rearing substrate.

In conclusion, calves reared on QS had lower skin surface temperatures and spent less time lying compared with calves reared on SW; however, we observed no differences in BW, cleanliness, or health. Lower skin temperature in combination with reduced lying behavior may reflect reduced comfort of calves reared on QS. Furthermore, calves reared at $2.0 \mathrm{~m}^{2} /$ calf spent more time standing and walking than calves reared at 1.0 or $1.5 \mathrm{~m}^{2} /$ calf, suggesting that more space may provide calves with more opportunity to perform active behaviors which is more likely to satisfy their behavioral needs. However, further research is needed to investi- gate the optimum space allowance required for rearing group-housed dairy calves.

\section{ACKNOWLEDGMENTS}

The authors gratefully acknowledge the assistance from AgResearch staff, especially Suzanne Dowling, Rose Greenfield, Frankie Huddart, Jessica Boersen, Gemma Lowe, Colleen Ross, and Delphine Rapp. AgResearch gratefully acknowledges that this study was funded by the NZ Ministry of Business, Innovation and Employment (Wellington, New Zealand), and by New Zealand dairy farmers through DairyNZ (Hamilton, New Zealand).

\section{REFERENCES}

AgResearch Micromanual. 2005. The Meat Industry Microbiological Methods Manual. 4th ed. J. Nills, ed. AgResearch, Hamilton, New Zealand.

Alsemgeest, S. P. M., I. E. Lambooy, H. K. Wierenga, S. J. Dieleman, B. Meerkerk, A. M. van Ederen, and T. A. Niewold. 1995. Influence of physical stress on the plasma concentration of serum amyloid-a (SAA) and haptoglobin (HP) in calves. Vet. Q. 17:9-12.

Camiloti, T. V., J. A. Fregonesi, M. A. G. von Keyserlingk, and D M. Weary. 2012. Short communication: Effects of bedding quality on the lying behavior of dairy calves. J. Dairy Sci. 95:3380-3383.

Færevik, G., K. Tjentland, S. Løvik, I. L. Andersen, and K. E. Bøe. 2008. Resting pattern and social behaviour of dairy calves housed in pens with different sized lying areas. Appl. Anim. Behav. Sci. 114:54-64.

Haley, D. B., A. M. de Passillé, and J. Rushen. 2001. Assessing cow comfort: Effects of two floor types and two tie stall designs on the behaviour of lactating dairy cows. Appl. Anim. Behav. Sci. 71:105-117.

Hänninen, L., A. M. de Passillé, and J. Rushen. 2005. The effect of flooring type and social grouping on the rest and growth of dairy calves. Appl. Anim. Behav. Sci. 91:193-204.

Heegaard, P. M. H., D. L. Godson, M. J. M. Toussaint, K. Tjørnehøj, L. E. Larsen, B. Viuff, and L. Rønsholt. 2000. The acute phase response of haptoglobin and serum amyloid A (SAA) in cattle undergoing experimental infection with bovine respiratory syncytial virus. Vet. Immunol. Immunopathol. 77:151-159.

Hill, T. M., H. G. Bateman, J. M. Aldrich, and R. L. Schlotterbeck. 2007. Effects of feeding rate of milk replacers and bedding material for calves in a cold, naturally ventilated nursery. Prof. Anim. Sci. 23:656-664.

Hill, T. M., H. G. Bateman, J. M. Aldrich, and R. L. Schlotterbeck. 2011. Comparisons of housing, bedding, and cooling options for dairy calves. J. Dairy Sci. 94:2138-2146.

Jensen, M. B., K. S. Vestergaard, and C. C. Krohn. 1998. Play behaviour in dairy calves kept in pens: The effect of social contact and space allowance. Appl. Anim. Behav. Sci. 56:97-108.

Larson, L. L., F. G. Owen, J. L. Albright, R. D. Appleman, R. C. Lamb, and L. D. Muller. 1977. Guidelines toward more uniformity in measuring and reporting calf experimental data. J. Dairy Sci. 60:989-991.

Norring, M., E. Manninen, A. M. de Passillé, J. Rushen, L. Munksgaard, and H. Saloniemi. 2008. Effects of sand and straw bedding on the lying behavior, cleanliness, and hoof and hock injuries of dairy cows. J. Dairy Sci. 91:570-576.

On-Farm Research. 2013. Calf Rearing in NZ. Accessed Dec. 12, 2013. http://www.nzcalfrearing.com.

Panivivat, R., E. B. Kegley, J. A. Pennington, D. W. Kellogg, and S. L. Krumpelman. 2004. Growth performance and health of dairy 
calves bedded with different types of materials. J. Dairy Sci. $87: 3736-3745$.

Sutherland, M. A., M. Stewart, and K. E. Schütz. 2013. Effects of two substrate types on the behaviour, cleanliness and thermoregulation of dairy calves. Appl. Anim. Behav. Sci. 147:19-27.

Tapkı, I., A. Şahin, and A. G. Önal. 2006. Effect of space allowance on behaviour of newborn milk-fed dairy calves. Appl. Anim. Behav. Sci. 99:12-20.
Tucker, C. B., D. M. Weary, M. A. G. von Keyserlingk, and K. A. Beauchemin. 2009. Cow comfort in tie-stalls: Increased depth of shavings or straw bedding increases lying time. J. Dairy Sci. 92:2684-2690. 